Volume 2021, No. 3

\title{
Research on Bearing Fatigue Life of New Type Tire Unloader based on Ncode DesignLife
}

\author{
Jingxiu Ling ${ }^{1,3,}$, Long Cheng ${ }^{2}$, Qianting Wang ${ }^{2}$, Xiao Guo ${ }^{3}$, Wanglong Zhang ${ }^{3}$, Qiao Li $^{3}$ \\ ${ }^{1}$ School of Mechanical and Automotive Engineering, Fujian University of Technology, Fuzhou, Fujian, \\ China \\ ${ }^{2}$ School of Material Science and Engineering, Fujian University of Technology, Fuzhou, Fujian, China \\ ${ }^{3}$ CSCEC Strait Construction and Development Co., Ltd, Fuzhou, China \\ *corresponding author
}

\begin{abstract}
The new tire unloading machine is used for unloading and turning over the giant radial tire (weighing 6t). During the turning process, due to the huge inertial force of the tire and the collision force between the plywood and the tire, the tire unloading machine bearing is subjected to complex alternating stresses. It is difficult to predict the fatigue life of a bearing. To this end, the paper combines Ncode DesignLife, ADAMS and Workbench numerical analysis platform to predict the fatigue life of tire unloading machine bearings. At the same time, the ISO bearing life standard calculation method is used to evaluate the bearing life and compare the two calculation results. The research results show that the simulation prediction of the bearing life at the lowermost rocker arm of the tire unloader is 2190.56h, and the bearing life of the uppermost guide wheel bearing is 2025.56h. Accordingly, the ISO prediction results are $1717.12 \mathrm{~h}$ and $1128.44 \mathrm{~h}$, which are basically in the same order of magnitude. It shows that the simulation method of bearing life prediction used in the article is reasonable. The research can provide theoretical guidance for the bearing type matching and service life of the giant tire unloader.
\end{abstract}

Keywords: giant tire, new tire unloader, bearing; Ncode, life prediction

\section{Introduction}

With the upgrading and development of modern machinery industry, bearings as important parts of modern machinery, have developed rapidly in terms of rotation accuracy and mechanical properties. As an important equipment in the process of tire processing, production, and unloading, the tire unloading machine has strict bearing selection. Inappropriate selected bearings will reduce the stability and life of the whole machine system, causing premature damage to the equipment. After that, it led to production safety accidents, especially for giant tires weighing more than 6t. The structure of the new tire unloader is shown in the Figure.1

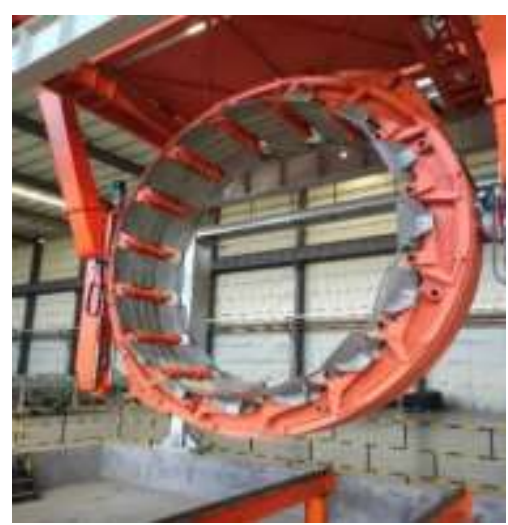

ISSN: 0010-8189

(c) CONVERTER 2020

www.converter-magazine.info 
Fig.1: The physical object of the new tire unloader.

At present, scholars are focusing on research on bearing materials, mechanical properties, fault judgment and life prediction. Lin and others are committed to modifying the existing life prediction model according to different bearing conditions and parameters to improve the accuracy of the life prediction results [1-6]. Liu et al. proposed a new bearing dynamics analysis model for flexible roller bearings, and analyzed the impact of bearing components on bearing vibration. The elastic deformation of surface rollers and races has a significant impact on the vibration of cylindrical roller bearings [7]. $\mathrm{Li}$ and others combined simulation software to study the temperature and stress distribution of the bearing under thermal stress, and predict the life of the bearing under the combined action of thermal stress and structural stress [8]. Lu et al. changed the production process of the bearing to improve the life of the bearing and reduce the noise of the bearing $[9,10]$. Herp et al. proposed a bearing state prediction method based on wind turbine bearing temperature residuals and Bayesian probability statistics. This method can predict bearing failures a week or even a month in advance [11]. Luo et al. solved the problems of bearing deformation, vibration, and failure by studying the force and stress distribution of the bearing, and provided a variety of solutions to the bearing contact problem [12-16]. Niu et al. studied the mechanical characteristics of the bearing under partial load and eccentric load through numerical and experimental methods, and put forward relevant suggestions for improvement $[17,18]$. Harrer studied a small all-ceramic rolling bearing used in the pharmaceutical industry, analyzed its failure mode through Raman spectroscopy. It is judged that this all-ceramic material is not the best choice in a high temperature and humid environment.[19]. CyrilSola and others are also dedicated to studying the mechanical properties of composite bearings, and proposed damage indicators for this type of bearing [20, 21].

To sum up, scholars at home and abroad have done a lot of research on the materials, processing technology, mechanical properties and life prediction methods of various bearings. However, there are few reports on the corresponding research in combination with specific equipment and cases, especially the unloading of giant tires. This article is based on a self-designed bearing of a new type of tire unloading machine, using simulation and theoretical methods to predict its life. The tire unloading machine is used for unloading and turning over a huge mining tire ( $6 \mathrm{t}$ ). During the working process, the huge inertial force and unexpected collision of the system will make the tire unloading machine bearing bear complex stress. So, this situation is likely to cause fatigue failure of the bearing and reduce the service life of the whole machine. To this end, this paper combines dynamics, statics and fatigue life with numerical simulation platforms to predict the fatigue life of bearings in important parts of the tire unloader. Among them, the life of important parts of the bearing has been calculated through numerical simulation, and the rationality of numerical simulation has been verified through theoretical calculation. So, it provides corresponding theoretical support for the selection, mechanical properties and safety of the bearings of the giant tire unloader.

\section{Life prediction model}

\subsection{Palmgren-Miner linear damage theory}

The linear damage theory believes that the total damage degree of a material is 1 , and each damage is the same under the same load cycle, and the damage degree can be linearly superimposed. When the damage degree is superimposed to 1 , the material is damaged. Assuming that the material is cycled ni times under $m$ different stress levels $\sigma \mathrm{i}$, the damage of one cycle is

$$
D=\sum_{i=1}^{m} \frac{n_{i}}{N_{i}}
$$

ISSN: 0010-8189

(C) CONVERTER 2020

www.converter-magazine.info 
In the formula, $\mathrm{Ni}$ represents the life of the material under stress $\sigma_{\mathrm{i}}$. The life $\mathrm{N}_{\mathrm{i}}$ under different stress levels can be obtained from the material SN curve. For steel, the SN curve can be conservatively estimated according to the material ultimate strength UTS. Figureure 2 shows the S-N curve of bearing steel automatically generated by the fatigue life numerical analysis platform according to the ultimate strength of the material.

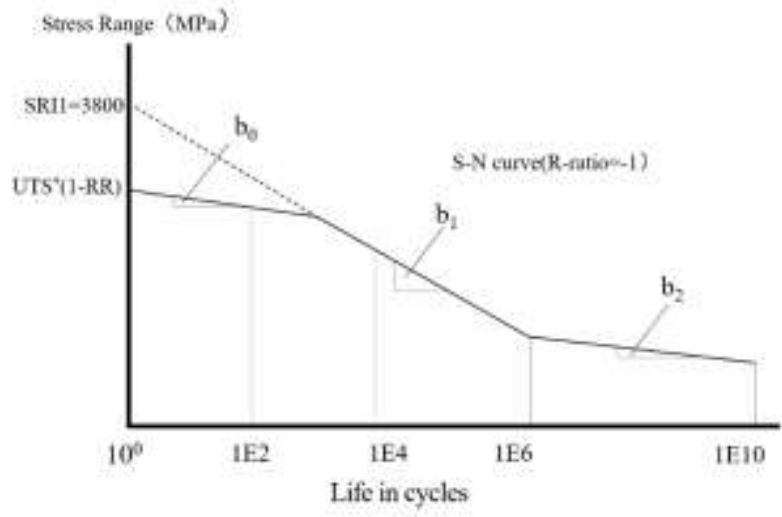

Fig.2: S-N curve of bearing steel.

In the Figureure, $b_{1}$ is the first fatigue strength index, $b_{2}$ is the second fatigue strength index, and SRI1 represents the stress value under one cycle.

In this paper, the stress time history of the bearing is obtained by the quasi-static method. The quasi-static method combines the finite element static stress results with the measured load time history to obtain the true stress history of the component. The specific definition is as follows.

$$
S(t)=\frac{(P(t) \text { ScaleFactor }+ \text { Offset }) S_{F E}}{\text { Divider }}
$$

In the formula, $\mathrm{S}(\mathrm{t})$ is stress time history during fatigue analysis; $S_{\mathrm{FE}}$ is the finite element solution static stress result, $\mathrm{P}(\mathrm{t})$ represents the time series load multiplier, ScaleFactor represents the actual load amplitude scale factor, Offset is user-defined, generally 0, and Divider is user-defined data.

The SN curve is generally a life curve measured according to the uniaxial tension of the material. In actual conditions, the stress on the bearing is generally multiaxial stress. The multiaxial stress needs to be combined into an equivalent stress, and the equivalent stress is compared with the material SN Curve to calculate life.The stress combination method adopts VonMises equivalent stress with sign, its expression is

$$
\sigma_{S V M}=\frac{\sigma_{A M P}}{\left|\sigma_{A M P}\right|}=\frac{1}{\sqrt{2}} \sqrt{\left(\sigma_{1}-\sigma_{2}\right)^{2}+\left(\sigma_{3}-\sigma_{2}\right)^{2}+\left(\sigma_{1}-\sigma_{3}\right)^{2}}
$$

In the formula, $\sigma_{1}, \sigma_{2}, \sigma_{3}$ represent the first, second, and third principal stresses, and $\sigma_{\mathrm{AMP}}$ is the maximum principal stress.

Rain flow is counted for the equivalent stress time history of the bearing, and the random load history is converted into a series of load cycles. After, frequency statistics are performed on the stress amplitude range of the series of load cycles, and the cumulative damage is calculated by the cyclic load.

The average stress is corrected for the load cycle obtained by the rain flow counting, and the life span of the stress amplitude under different stress ratios is converted into an S-N curve to determine the stress amplitude under the

ISSN: 0010-8189

(c) CONVERTER 2020

www.converter-magazine.info 
Volume 2021, No. 3

stress ratio. Wherein, the FKM standard of the German Society of Mechanical Engineering is adopted as the average stress correction method. Among them, the FKM curve is composed of four straight lines with different slopes, and the different slopes represent different average stress sensitivity. The curve is shown in Figure 3.

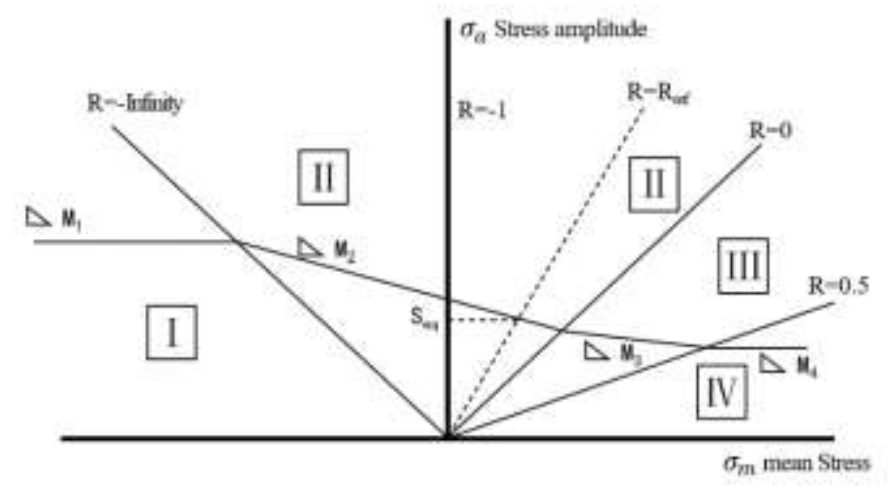

Fig.3: FKM correction.

The values of $\mathrm{M}_{1}, \mathrm{M}_{2}, \mathrm{M}_{3}$, and $\mathrm{M} 4$ can be determined according to material tests or estimated according to formulas. The formula is as follows.

$$
\begin{aligned}
& M_{1}=0, \quad M_{2}=-M_{\sigma}, \quad M_{3}=-M_{\sigma} / 3, \quad M_{4}=0 \\
& M_{\sigma}=10^{-3} a_{M} R_{m}+b_{M}
\end{aligned}
$$

In the formula, $a_{\mathrm{M}}$ and $b_{\mathrm{M}}$ are constants, and $R_{\mathrm{m}}$ represents the tensile strength.

After obtaining the different stress amplitudes under a specific stress ratio, the damage degree D of one cycle can be calculated according to the formula (1) combined with the S-N curve. Finally, the total number of cycles, that is, the lifetime value is $1 / \mathrm{D}$.

\subsection{L-P bearing life prediction theory}

In this paper,the ISO standard bearing approximate fatigue life prediction formula is used to predict the lifeof bearings. The specific expression is shownin equation (5).

$$
L_{h}=\frac{10^{6}}{60 n}\left(\frac{C}{P}\right)^{\varepsilon}
$$

In the formula, $C$ is the rated dynamic load, $P$ is the equivalent dynamic load, $\varepsilon$ is the life index, the ball bearing is taken as 3 , and $\mathrm{Lh}$ is the rated life of the bearing in hours, $\mathrm{n}$ is the bearing speed, and both bearings take $30 \mathrm{r} / \mathrm{min}$.

This article focuses on using the fatigue life numerical analysis platform to predict the life of the tire unloading machine bearing, combined with theoretical calculations for comparative analysis. The specific prediction process is shown in Figure 4.

ISSN: 0010-8189

(c) CONVERTER 2020 


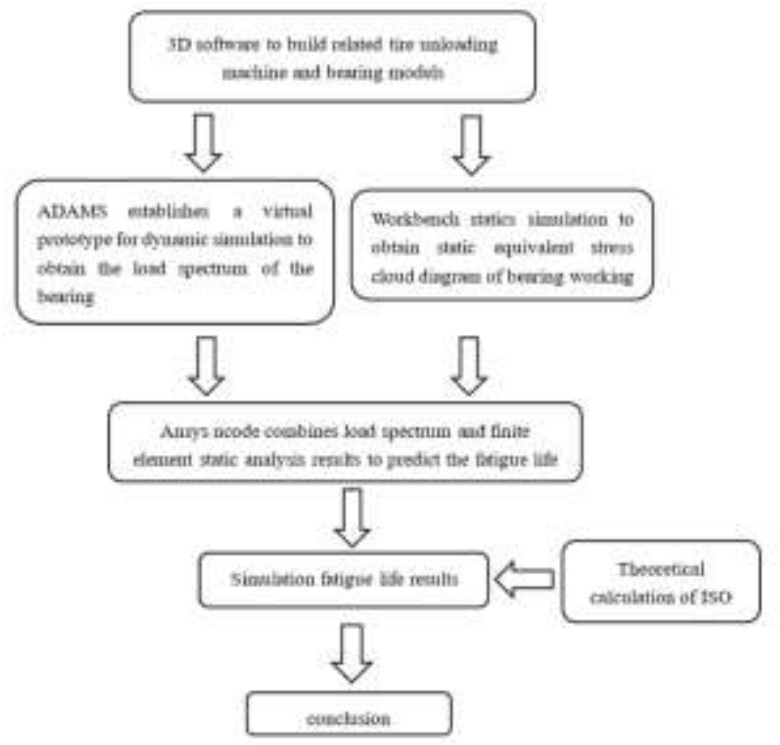

Fig.4: Flow chart of bearing fatigue life prediction.

\section{Example analysis}

3.1 Example structure overview of the new tire unloader

The tire unloading machine studied in this paper is used for the loading and unloading of the new type of radial giant tires. During the tire processing and production, it is used to unload $6 \mathrm{t}$ of mining tires and carry out the next production process. The specific structure is composed of clamping plate, rocker arm, guide rail axle, rocker arm, moving ring and fixed ring, as shown in Figure 5. During operation, the motor drives the guide rail wheel shaft to rotate, the guide rail wheel shaft controls the movement of the connecting rod on the fixed ring, and the connecting rod drags the splint on the rocker arm to clamp the tire. After clamping, the whole machine and the tire are turned over $90^{\circ}$ from the rotating part to complete the unloading of the tire.

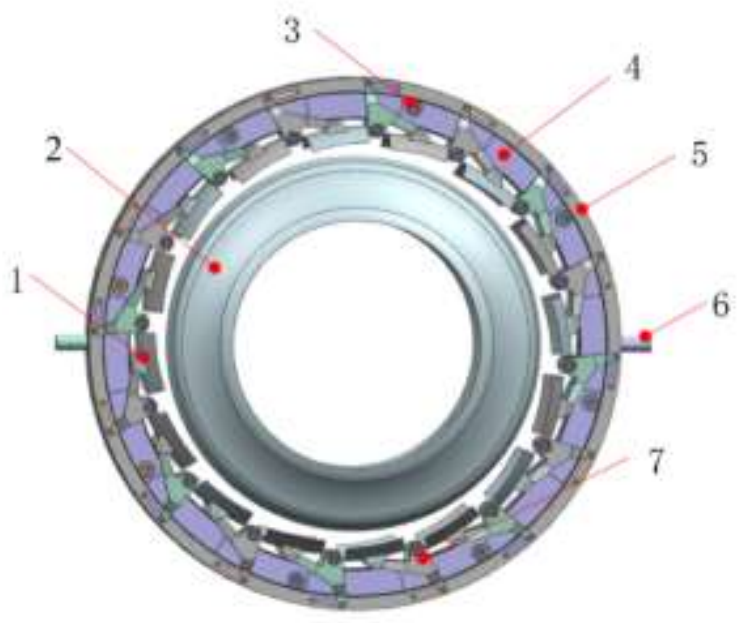

Fig.5:Structure diagram of the new type tire unloading machine (1) Splint (2) Tire (3) Guide wheel (4) Fixed ring (5) Moving ring (6) Slewing part (7) Bearing at the bottom rocker arm.

ISSN: 0010-8189

(c) CONVERTER 2020 
Volume 2021, No. 3

The tire unloader has 16 pairs of rocker arms and 8 guide wheels. Wherein, each rocker arm and the rotating part ofthe guide wheel are equipped with two bearings of the same type. Among them, the bearing model at the rocker arm is deep groove ball 61918 bearing, and deep groove ball 61818 bearing is installed at the guide wheel. During the turning process, the mechanism bearing force is more complicated. In addition to the gravity and turning inertia force of the system itself, there is also the force generated by the friction and collision between the tire and the splint, which affects the mechanical characteristics and performance of the bearing. So, this paper uses ADAMS dynamics software to establish a virtual prototype of the tire unloader, and simulates the working conditions of the tire unloader to obtain the load spectrum of the bearing at the lowermost rocker arm and the bearing at the uppermost rail axle. These results are shown in Figureure 7and8. Simultaneously, the fatigue life prediction of the two parts of the bearing is carried out in combination with the statics and life prediction simulation platform.

\subsection{Prediction of bearing fatigue life}

\subsubsection{Determination of bearing load of tire unloader}

The 3D model of tire unloader is imported into Adams in Parasolid format, and the material parameters of tire unloader and tire are set up.Then, the constraint pairs are established according to the motion of each mechanism. Among them, the hinge position of the splint, the fixed ring rotation part, the guide wheel and the shaft establish a rotating pair. In addition, the rocker arm and the guide rail wheel axle are fixedly connected with the fixed ring through the fixed pair. At the beginning, the tire uses a fixed pair. After the tire is clamped by the tire unloader, the fixed pair fails, and the tire rotates with the tire unloader. The process of fixing and failing the tire is controlled by a script program. Furthermore,the spring unit is used to simulate the supporting bearings at the mechanism, the contact collision force simulates the contact of each member, and gravity is applied as an external load.Finally, rotational drive is applied to the rotating part, and the moving ring is point-driven (to avoid over-constraint) to complete the establishment of the virtual prototype of the tire unloading system, as shown in Figureure 6. The step size is set to $0.01 \mathrm{~s}$ for dynamic simulation. The uppermost rail axle of the tire unloading machine mainly bears the weight of the moving ring. When the tire unloading machine is turned, the lowermost rocker arm farthest from the rotating shaft receives the largest centrifugal inertia force and gravity component of the tire. So,the bearings in these two places are used as the analysis in this paper. The key point of the simulation is to obtain the three-way load spectrum of the bearing at the bottom rocker arm and the bearing at the top rail wheel. The simulation results are shown in Figure 7 and 8.

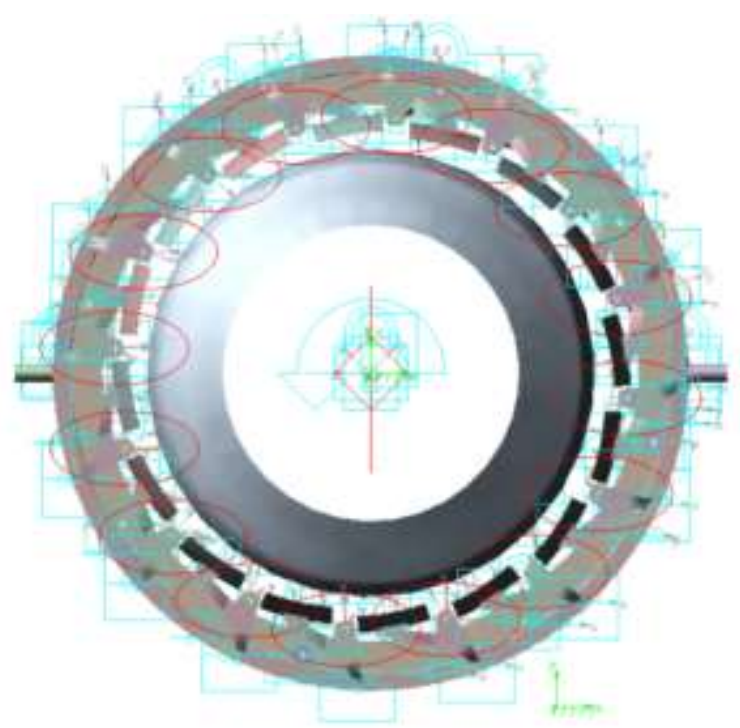

Fig.6: Virtual prototype model of tire unloading machine.

ISSN: 0010-8189 


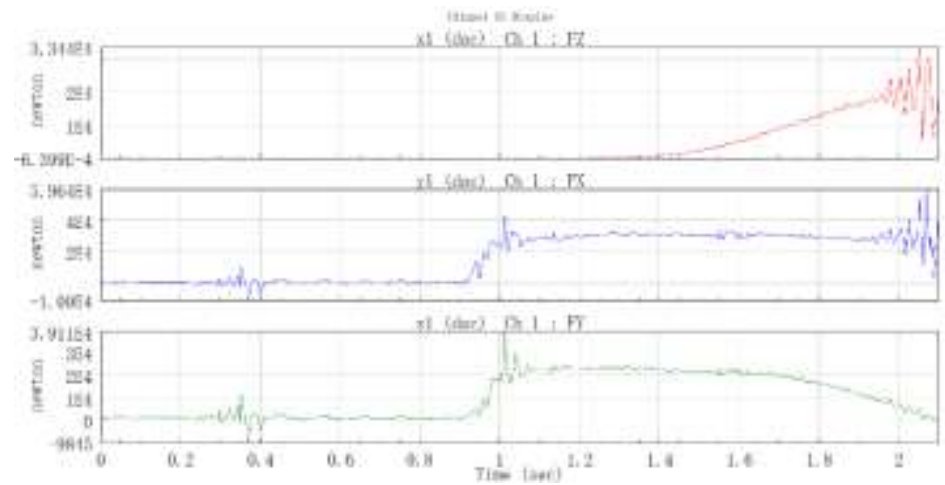

Fig.7: Three-directional force load spectrum of the bearing at the lowermost rocker arm.

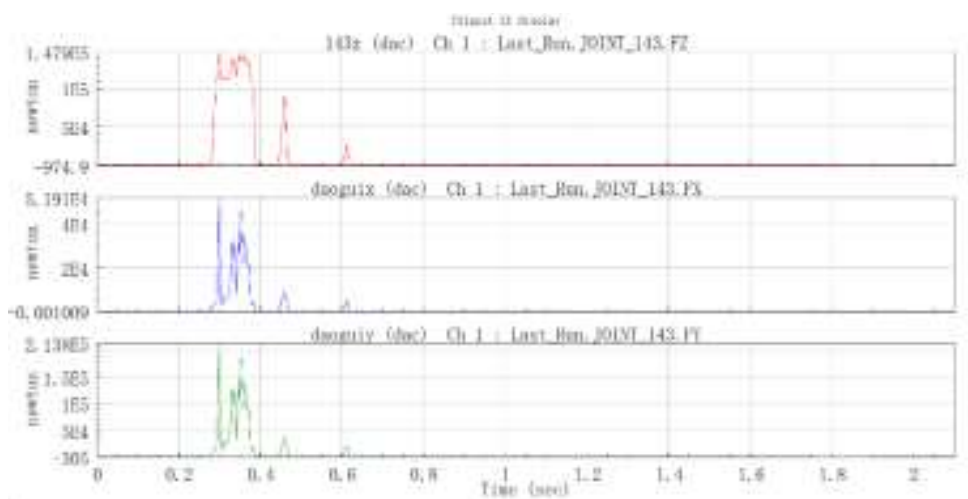

Fig.8: Three-way force load spectrum of the bearing at the top rail wheel.

3.3 Bearing static stress analysis under standard conditions

According to the above formula (2), the stress time history of the bearing is obtained by the quasi-static method, and the static stress results of the bearing under different working conditions are required. Workbench is used to analyze the static stress of the bearing under different working conditions.

\subsubsection{Nonlinear finite element model}

The bearing at the bottom rocker arm of the tire unloading machine is a deep groove ball 61918 bearing. Using proe 3D modeling software to model the bearing 61918 , omitting non-important parts such as cages. The model parameters are shown in Table 1, and the 3D model is shown in Figure 9.

Table 1 Bearing geometry.

\begin{tabular}{|c|c|c|c|}
\hline $\begin{array}{c}\text { Bearing } \\
\text { Type }\end{array}$ & $\begin{array}{c}\text { Outer diameter } \\
(\mathrm{mm})\end{array}$ & $\begin{array}{c}\text { Internal } \\
\text { diameter } \\
(\mathrm{mm})\end{array}$ & $\begin{array}{c}\text { Thickness } \\
(\mathrm{mm})\end{array}$ \\
\hline 61918 & 125 & 90 & 18 \\
\hline
\end{tabular}

ISSN: 0010-8189

(c) CONVERTER 2020 


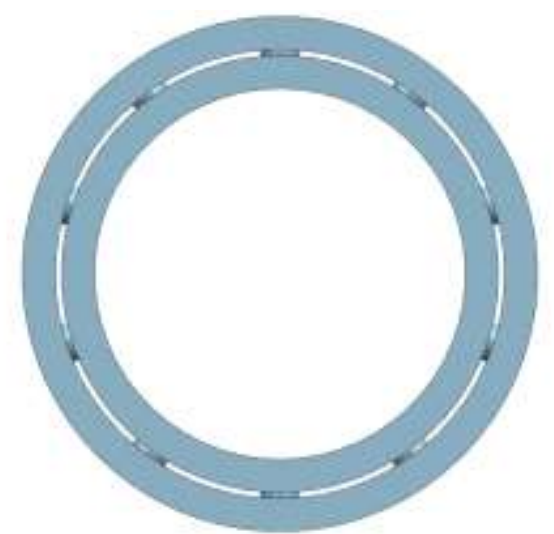

Fig.9:Three-dimensional model of bearing 61918.

Importing the model into ANSYS Workbench in Parasolid format for statics simulation and set the material parameters. Both types of bearings use ordinary bearing steel materials. The relevant bearing material parameters are shown in Table 2.

Table 2 Bearing material parameters.

\begin{tabular}{|c|c|c|c|c|}
\hline Material & $\begin{array}{c}\text { Elastic } \\
\text { Modulus } \\
(\mathrm{MPa})\end{array}$ & $\begin{array}{c}\text { Poisson's } \\
\text { ratio }\end{array}$ & $\begin{array}{c}\text { Yield } \\
\text { Strength } \\
(\mathrm{MPa})\end{array}$ & $\begin{array}{c}\text { Tensile } \\
\text { strength } \\
(\mathrm{MPa})\end{array}$ \\
\hline $\mathrm{GCr} 15$ & 210000 & 0.29 & 1458 & 1617 \\
\hline
\end{tabular}

The roller has frictional contact with the inner and outer rings. First, the algorithm is augmented Lagrangian, and the normal stiffness is set to 1, to ensure the convergence of the calculation and the accuracy of the result. Second, the bearing is meshed and boundary conditions are imposed. The bearing at the lowermost rocker arm of the tire unloader is fixed on the outer ring, and the inner ring is stressed. Bearings are mainly subjected to loads in three directions, which are divided into three working conditions. After that, static analysis of these three working conditions was carried out.. Finally, the effects of loading and boundary condition settings are shown in Figures 10 to 12 .

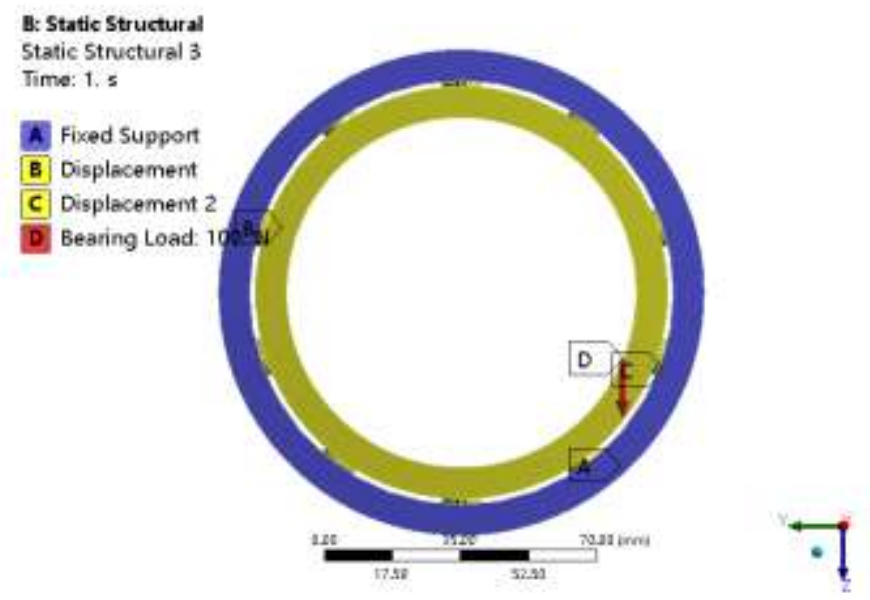

Figure.10: Vertical force loading.

ISSN: 0010-8189

(c) CONVERTER 2020 
Cstatic Structurs

Time 1 s

A Fixed Suppon

B Displacement

C Displacement 2

D. Force $100 . \mathrm{N}$

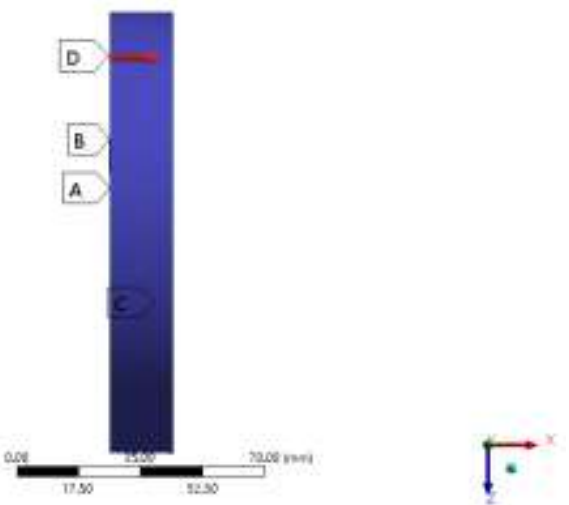

Figure.11: Axial force loading.

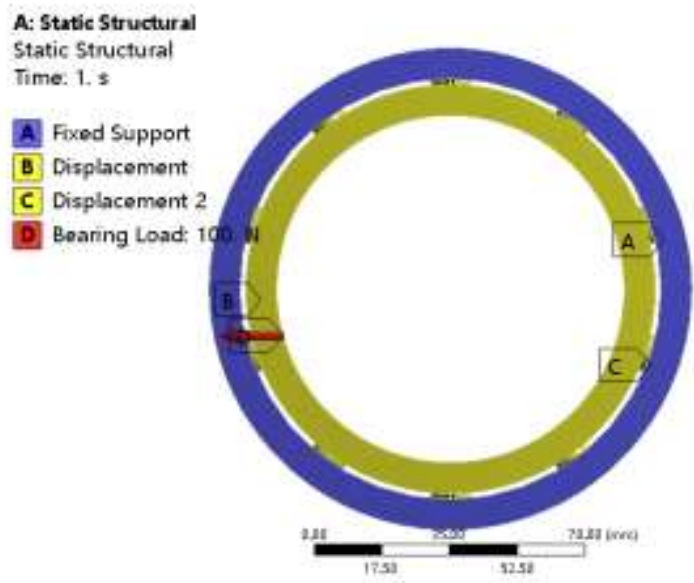

Fig12: Lateral force loading.

Co-simulate the three working conditions to view the stress cloud diagram, as shown in Figure 13-15.

Equivalent Stress 2

Type: Equivalent (von-Mises) Stress

Unit: MPa
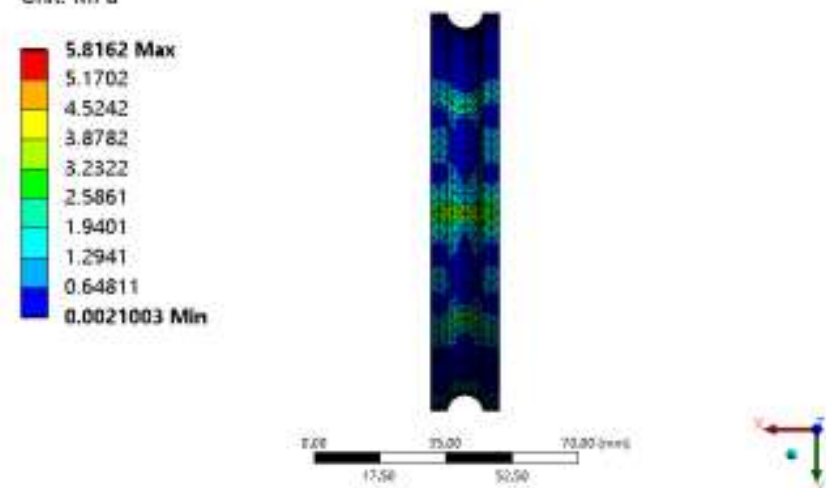

Fig.13: Equivalent stress cloud diagram of bearing 61918 inner ring joint simulation.

ISSN: 0010-8189

(c) CONVERTER 2020

www.converter-magazine.info 
tquivalent Stress 3 Type: Equivalem (von-Mises) Strens Unit MPa

\begin{tabular}{|l}
$5.7279 \mathrm{Mmx}$ \\
5.0915 \\
4.455 \\
3.8186 \\
3.1822 \\
2.5457 \\
1.9093 \\
1.2729 \\
0.63643 \\
$5.5215 \mathrm{e}-11 \mathrm{Mn}$
\end{tabular}
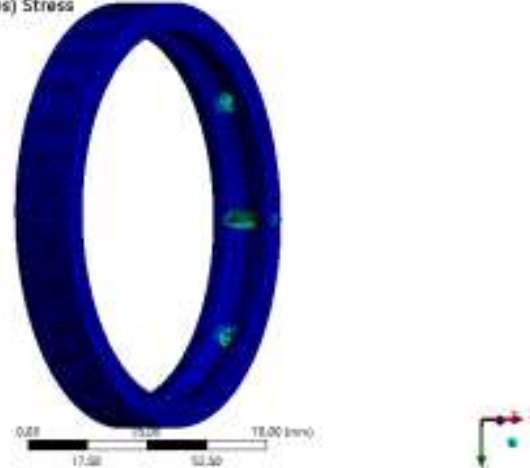

Figure.14: Equivalent stress cloud diagram of bearing 61918 outer ring joint simulation.

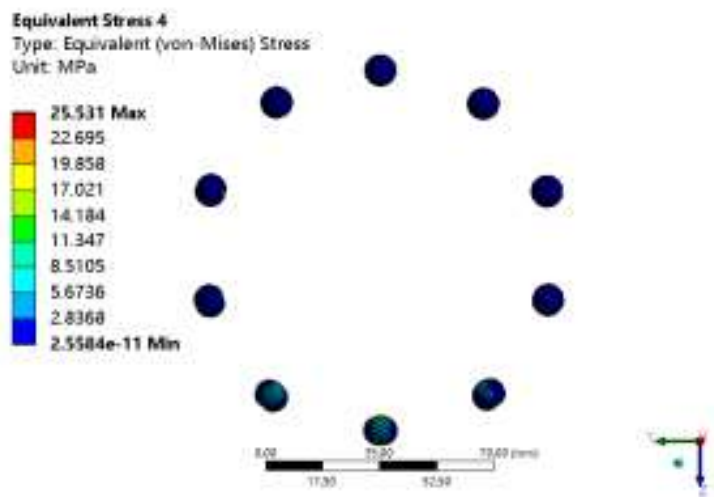

Fig.15: Equivalent stress cloud diagram of bearing 61918 ball joint simulation.

\subsection{Bearing fatigue life prediction}

The ncode analysis module is built on the ANSYS Workbench platform. Then imported the three finite element analysis results and the load spectrum obtained from the dynamic analysis into the nCode life analysis module. After completing the above steps, proceed to material mapping, parameter and solution settings. Moreover, the three finite element stress analysis results are unitized and mapped to the load spectrum. Because two identical bearings are installed in the analyzed part, the ScaleFactor of lateral force and vertical force load is set to 0.5 . The obtained fatigue life cloud chart is shown in Figure 16.

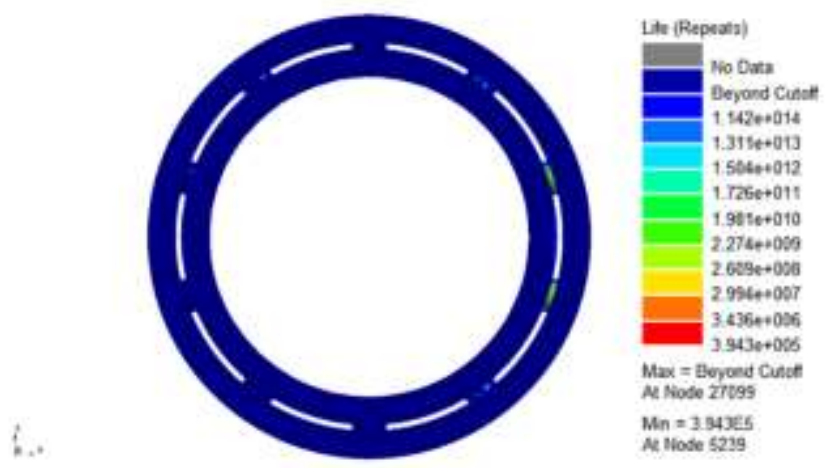

Fig.16: Fatigue life cloud diagram of bearing 61918.

ISSN: 0010-8189

(c) CONVERTER 2020

www.converter-magazine.info 
According to the cloud chart, the final life span is 394,300 times, which is $2190.56 \mathrm{~h}$ in hours.

The bearing 61818 at the top rail wheel adopts the same analysis method, and the working conditions are similar. The three-dimensional model of the bearing 61818 is established as shown in Figure 17. The dynamic analysis of the ADAMS tire unloader obtains the three-directional load spectrum at the rail wheel bearing as shown in Figure 8.The condition is that the inner ring raceway is fixed and the outer ring rotates with the fixed ring. For the combined statics simulation of the three working conditions of the bearing, the overall stress cloud diagram is shown in Figure 18. Finally, the fatigue life of the bearing is analyzed, and the cloud diagram is shown in Figure 19.

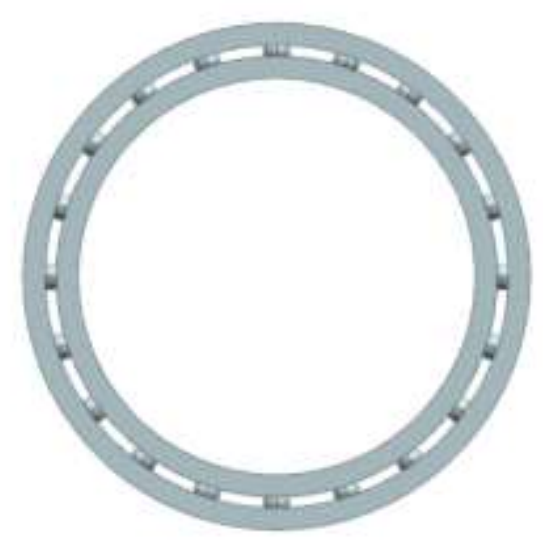

Figure.17:Three-dimensional model of deep groove ball bearing 61818.

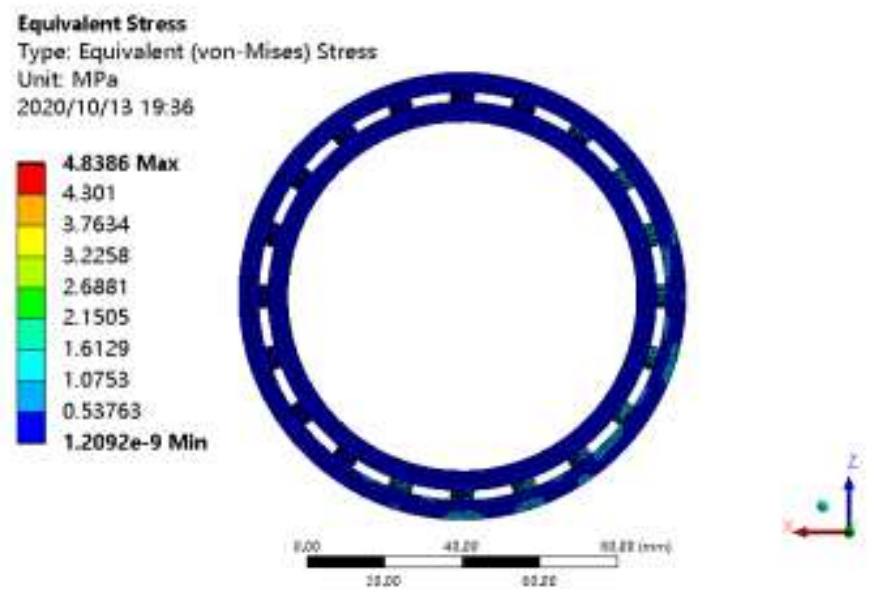

Fig.18: Joint simulation overall stress cloud diagram of bearing 61818.

ISSN: 0010-8189

(c) CONVERTER 2020

www.converter-magazine.info 


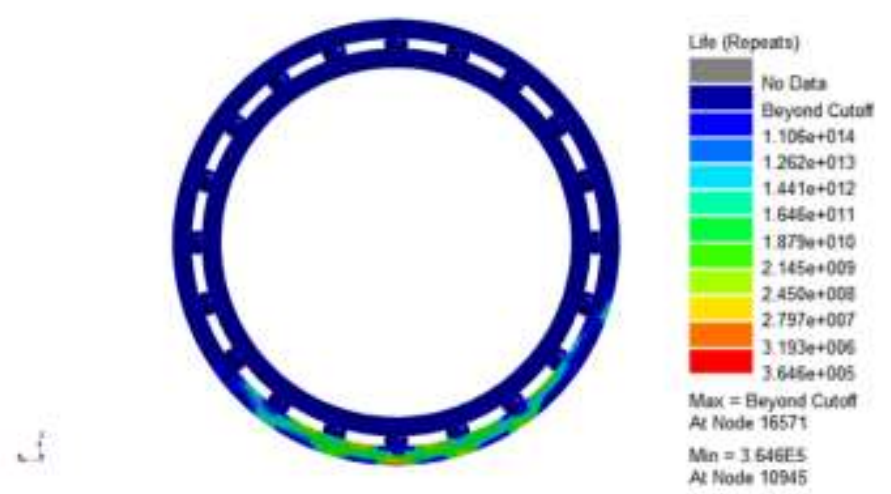

Figure.19:61818 bearing life cloud diagram.

According to the life cloud diagram, the bearing life is 364,600 times, and the equivalent time is $2025.56 \mathrm{~h}$. The first place where fatigue failure occurs is the outer ring in contact with the fixed ring, which conforms to the actual situation.

\section{ISO standard method prediction of bearing life}

The bearing model used in this article is 61918 , which is a deep groove ball bearing. The query can get its rated dynamic load $\mathrm{Cr}=33500 \mathrm{~N}$ and rated static load $\mathrm{Cor}=30500 \mathrm{~N}$.

The bearing at the rocker arm is mainly subjected to three-directional forces, which are lateral force, vertical force, and axial force transmitted to the bearing through the shaft shoulder. The radial force and the axial force are converted into equivalent loads for life calculation. The conversion formula is shown in the following formula.

$$
P=f_{p}\left(X F_{r}+Y F_{z}\right)
$$

In the formula, $F_{\mathrm{r}}$ is the radial load, $F_{\mathrm{z}}$ is the axial load, and $f_{\mathrm{p}}$ is the load factor, which is selected according to the impact degree of the load.

Because the load in each direction is variable and the range of change is large. So, this paper calculates the effective equivalent load based on the highest load value in the stable part of the load spectrum. The required stable load value can be directly extracted in the ADAMS post-processing The three-directional forces $F_{\mathrm{x}}, F_{\mathrm{y}}, F_{\mathrm{z}}$ is $31200.17 \mathrm{~N}, 22264.65 \mathrm{~N}$ and $4099.75 \mathrm{~N}$ respectively. Because there are two bearings to realize the support, the vertical force and the lateral force need to be halved. So The final load can be $F_{\mathrm{x}}=15600.09 \mathrm{~N}, F_{\mathrm{y}}=11132.33 \mathrm{~N}$, $F_{\mathrm{z}}=4099.75 \mathrm{~N}$.

According to the relative axial load to obtain the parameter e, the relative axial load is calculated as

$$
\frac{F_{Z}}{C_{\text {or }}}=\frac{4099.75}{30500}=0.13
$$

Check the ISO table and calculate according to linear interpolation, $\mathrm{e}=0.31$, the radial force Fr is:

$$
F_{r}=\sqrt{F_{x}+F_{y}}=\sqrt{15600.09^{2}+11132.33^{2}}=19164.85 \mathrm{~N}
$$

The ratio of the axial force to the radial force is compared with the parameter e to select the dynamic load coefficient $\mathrm{X}, \mathrm{Y}$.

$$
\frac{F_{z}}{F_{r}}=4099.75 N / 19164.85 N=0.21
$$

ISSN: 0010-8189 
Take $\mathrm{X}=1, \mathrm{Y}=0$, take the medium impact load 1.2 according to the working condition $f_{p}$; According to the formula (6) $P=22997.82 \mathrm{~N}$, substituting the formula (5) can get $L_{\mathrm{h}}=1717.12 \mathrm{~h}$.

Similarly, the guide wheel bearing is 61818 , the rated static load is $20500 \mathrm{~N}$, and the rated dynamic load is $19500 \mathrm{~N}$. The three-directional load values is $F_{\mathrm{x}}=788.72 \mathrm{~N}, F_{\mathrm{y}}=3329.06 \mathrm{~N}, F_{\mathrm{z}}=10495.56 \mathrm{~N}$. e=0.43.X=0.56, Y=1.02, the load factor $f_{p}$ is $1.2, P=15145.63 \mathrm{~N}, L_{\mathrm{h}}=1185.69 \mathrm{~h}$. Compare the simulation results with the theoretical calculation results and present them in the table3.

Table 3 Comparison of theoretical calculation life time and simulation time.

\begin{tabular}{|c|c|c|}
\hline Bearing Type & $\begin{array}{c}\text { Theoretical calculation } \\
\text { life value }(\mathrm{h})\end{array}$ & $\begin{array}{c}\text { Simulation } \\
\text { life value }(\mathrm{h})\end{array}$ \\
\hline $\begin{array}{c}\text { Deep groove } \\
\text { ball } 61918\end{array}$ & 1717.12 & 2190.56 \\
\hline $\begin{array}{c}\text { Deep groove } \\
\text { ball } 61818\end{array}$ & 1185.69 & 2025.56 \\
\hline
\end{tabular}

By the two methods, it can be seen that the theoretically calculated life value is generally small. but it is consistent with the change trend of the simulation value and is of the same magnitude, which shows that the bearing simulation prediction method in this paper is more reasonable. Judging from the two results, the first bearing failure occurred at the 61818 bearing at the top guide wheel. The bearing here bears a larger axial impact load, which has a greater impact on the life of this type of deep groove ball bearing.

\section{Conclusion}

Based on the tire unloading machine bearing of the giant tire, this paper combines the dynamics, statics, fatigue life simulation platform and the ISO life calculation method to predict the life of this kind of bearing. The conclusions are as follows:

(1) The fatigue life of the lowermost rocker arm of the tire unloading machine is $2190.56 \mathrm{~h}$, and the first part of the damage is the ball.

(2) The service life of the bearing on the top rail wheel of the tire unloader is $2025.56 \mathrm{~h}$. And than,the first place where fatigue failure occurs is the outer ring in contact with the fixed ring, which is in line with the actual situation. (3) According to the ISO standard calculation of the two types of bearings, the service life is $1717.12 \mathrm{~h}$ and $1185.69 \mathrm{~h}$. The above values are of the same magnitude as the simulation results, and the trend of size changes is the same. Since the stable load value at the highest peak is used to calculate the equivalent load, the life calculation result is conservative than the simulation result.

(4)A comprehensive comparison of the theoretical estimation and simulation results of the two bearings can draw the following conclusions. The first bearing to be damaged is the bearing at the top guide wheel of the tire unloader. The bearing here suffers a greater axial impact load, which has a greater impact on the life of the deep groove ball bearing. Therefore, other types of bearings can be considered.

In this paper, the ISO standard calculation method is used to calculate the bearing life, and the highest load value in the stable load spectrum is selected to calculate the equivalent load. Although the result is safe, there is a certain gap with the actual bearing life. At the same time, the fatigue life under different reliability is also a very important content. As the service life of the tire unloader increases, its reliability will change accordingly. Therefore, the next work can be the impact load of the bearing Perform statistical processing, convert the load history into cyclic loads, compile the program load spectrum, and use the revised SN curve to predict the bearing life. These work can make bearing life prediction results more accurate. In addition, the relationship between bearing life and reliability can

ISSN: 0010-8189

(c) CONVERTER 2020

www.converter-magazine.info 
be explored according to the relevant fatigue reliability theory, and the research on the fatigue reliability of the bearing of tire unloader can be improved.

\section{Acknowledgment}

This work was supported by the China Postdoctoral Science Foundation (Granted No. 2020M671956), Natural Science Foundation of Fujian (Granted No. 2020J01871) and Scientific Research Foundation of Fujian University of Technology (Granted No.GY-Z160048).

\section{References}

[1]. Fen Lin, Jie Tang, Zhao Youqun, et al Analysis of wheel bearing load distribution and bending fatigue life based on modified L-P model. China Mechanical Engineering, vol: 031, no: 008, pp.898-906, 2020.

[2]. Xiujiang Shi, Liqin Wang, Fenqi Qin. Relative fatigue life prediction of high-speed and heavy-load ball bearing based on surface texture. Tribology International, no: 101, pp.364-374, 2016.

[3]. Liu Dekun,Li Qiang, Wang Xi, et al. Life prediction method for axlebox bearings of EMUs based on measured loads. Chinese Journal of Mechanical Engineering, vol: 52, no: 22, pp.45-54, 2016.

[4]. A. Bryan, P Anup. Critical. Critical factors for determining a first estimate of fatigue limit of bearing steels under rolling contact fatigue. International Journal of Fatigue, no: 117, pp.:396-406, 2018.

[5]. Mingming Yan, Xingang Wang, Bingxiang Wang, et al. Bearing remaining useful life prediction using support vector machine and hybrid degradation tracking model. ISA Transactions, no: 98, pp.471-482, 2020 .

[6]. Jin Cui, Lei Ren, Xiaokang Wang, et al. Pairwise comparison learning based bearing health quantitative modeling and its application in service life prediction Future Generation Computer Systems, no:97, pp.578-586, 2019.

[7]. Jing Liu, Changke Tang, Yimin Shao. An innovative dynamic model for vibration analysis of a flexible roller bearing. Mechanism and Machine Theory, no: 135, pp.27-39, 2019.

[8]. Miaomiao Li, Yang Yang, Yu Wang, et al. Simulation of fatigue life of angular contact ball bearings considering temperature effects. Machinery Manufacturing \& Automation, vol: 049, no: 002, pp.113-116, 2020.

[9]. Xiaohui Lu, Qian Dongsheng, Li Wei, et al. Enhanced toughness of bearing steel by combining prior cold deformation with martensite pre-quenching and bainite transformation. Materials Letters, vol: 234, no: 1, pp. 5-8, 2019.

[10]. Zhaoxi Cao, Tianqi Liu, Feng Yu, et al. Carburization induced extra-long rolling contact fatigue life of high carbon bearing steel. International Journal of Fatigue, vol: 131, pp.1-6, 2020.

[11]. H. Jürgen, M H Ramezani, Bach-Andersen M , et al. Bayesian state prediction of wind turbine bearing failure. Renewable Energy, vol: 116, pp. 164-172, 2017.

[12]. Tianyu Luo, Jiwei Luo. The preload and stiffness of angular contact ball bearings. Bearings, no: 06, pp. $1-4,2015$.

[13]. Jinhua Zhang, Bin Fang, et al. Effect of preload on ball-raceway contact state and fatigue life of angular contact ball bearing. Tribology International, no: 114, pp. 365-372, 2017.

[14]. Yuze Mao, Liqin Wang, Chi Zhang. Influence of ring deformation on the dynamic characteristics of a roller bearing in clearance fit with housing. International Journal of Mechanical ences, no: 138-139, pp. 122-130, 2018.

[15]. Jing Liu, Zhifeng Shi, Yimin Shao. A numerical investigation of the plastic deformation at the spall edge for a roller bearing. Engineering Failure Analysis, no: 80, pp. 263-271, 2017.

[16]. Ting Lin. Research on bearing force applied to the alignment calculation of cutter shaft system of cutter suction dredger, Shanghai Jiaotong University, 2019.

[17]. Rongjun, Yusheng Hu, Yonggang Wang, et al. Simulation analysis of load-bearing performance of locally loaded needle roller bearings. Journal of Aeronautics and Dynamics, no: 10, pp. 2227-2236,

ISSN: 0010-8189

(C) CONVERTER 2020 
2019.

[18]. Lihuang Yang, Tengfei $\mathrm{Xu}$, Haoliang $\mathrm{Xu}$, et al. Mechanical behavior of double-row tapered roller bearing under combined external loads and angular misalignment. International Journal of Mechanical Sciences, no: 142-143, pp. 561-574, 2018.

[19]. W. Harrer, M. Deluca, R .Morrell. Failure analysis of a ceramic ball race bearing made of Y-TZP zirconia. Engineering Failure Analysis, no: 36, pp. 262-268, 2014.

[20]. S .Cyril, C. Bruno, M. Laurent, et al. Bearing fatigue of composite laminates: Damage monitoring and fatigue life prediction. Composites Part B, no: 110, pp. 487-496. 2017.

[21]. Fujian Zhuang, Puhui Chen. Arteiro Albertino,et al. Mesoscale modelling of damage in half-hole pin bearing composite laminate specimens. Composite Structures, no: 214, pp. 191-213, 2019. 